\title{
Factors influencing women's willingness to volunteer in the healthcare system: evidence from the Islamic Republic of Iran
}

A. Alami, ${ }^{1,2}$ S. Nedjat, ${ }^{2,3}$ R. Majdzadeh, ${ }^{2,3}$ A. Rahimi Foroushani, ${ }^{2}$ S.J. Hoseini ${ }^{4}$ and H. Malekafzali ${ }^{2}$

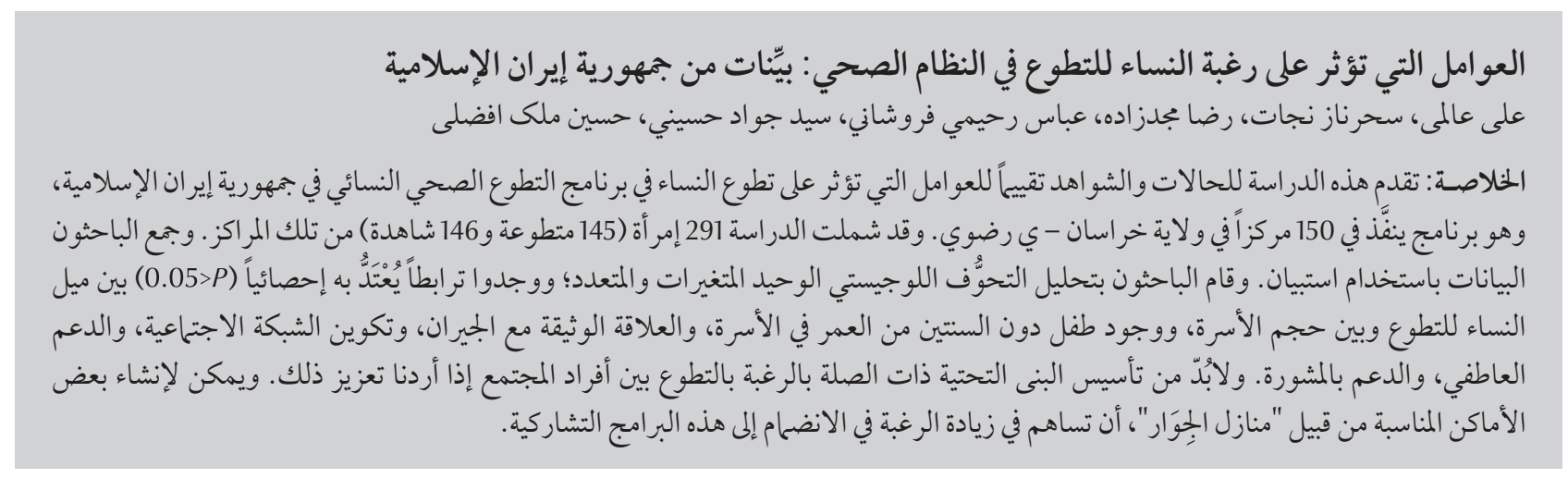

ABSTRACT This case-control study evaluated the factors influencing volunteering in the Islamic Republic of Iran's Women's Health Volunteer (WHV) programme, which is implemented in 150 centres in Khorasan-e-Razavi Province. We recruited 145 cases (volunteers) and 146 controls (non-volunteers) from the centres. Data were collected by questionnaire. Sociodemographic variables included were: length of residence in neighbourhood, number of siblings, husband's age and education and job, family size, quality of life, self-rated health status, neighbourhood intimacy, child under 2 years, house ownership, wealth index. Social network variables included were: ego network size, type of acquaintance, intimacy with others, relationship communication, relationship duration, emotional support, advisory support, monetary support, physical support, time support. There were significant associations $(P<0.05)$ between women's propensity to volunteer and family size, presence of a child under 2 years in the family, neighbourhood intimacy, social network composition, and emotional and advisory support.

Facteurs influençant l'intention des femmes à devenir volontaires dans le système de soins de santé : données provenant de la République islamique d'Iran

RÉSUMÉ La présente étude cas-témoin a évalué les facteurs influençant le volontariat dans le programme Femmes volontaires de la santé en République islamique d'Iran, mis en œuvre dans 150 centres de la province du KhorassanRazavi. Nous avons recruté 145 cas (participation volontaire) et 146 témoins (participation sollicitée) dans ces centres. Des données ont été recueillies par questionnaire. Les variables sociodémographiques prises en compte étaient les suivantes : la durée de résidence dans le voisinage, le nombre de frères et sœurs, l'âge du mari, son niveau d'études et son emploi, la taille de la famille, la qualité de vie, l'état de santé auto-évalué, le degré de connaissance du voisinage, la présence ou non d'un enfant de moins de deux ans dans la famille, le fait d'être propriétaire de son logement et l'indice de richesse. Les variables des réseaux sociaux prises en compte étaient les suivantes : la taille du réseau égocentré, le type de connaissance, le degré d'intimité avec les autres, la communication relationnelle, la durée des relations, le soutien psychologique, l'appui consultatif, le soutien financier, le soutien physique et le soutien à la personne. Des corrélations significatives $(P<0,05)$ ont été trouvées entre la propension des femmes à devenir volontaires et la taille de la famille, la présence ou non d'un enfant de moins de deux ans, le degré de connaissance du voisinage, la composition du réseau social, et le soutien psychologique et consultatif.

${ }^{7}$ School of Public Health, Social Development and Health Promotion Research Centre, Gonabad University of Medical Sciences, Gonabad, Khorasan Razavi, Islamic Republic of Iran. ${ }^{2}$ Department of Epidemiology and Biostatistics, School of Public Health; ${ }^{3}$ Knowledge Utilization Research Centre, Tehran University of Medical Sciences, Tehran, Islamic Republic of Iran (Correspondence to S. Nedjat: nejatsan@tums.ac.ir). ${ }^{4}$ Health Centre of Khorasan-e-Razavi Province, Mashad University of Medical Sciences, Mashad, Islamic Republic of Iran.

Received: 28/08/11; accepted: 2/12/11 


\section{Introduction}

\section{Participation and volunteering}

Since the World Health Organization's "Health for All" Strategy was devised in 1979, participation has been considered a subject central to health. The important role of participation in health promotion strategies was re-emphasized in the "Ottawa Charter for Health Promotion" in 1986 [1]. Participation may be defined as "a process by which people are enabled to become actively and genuinely involved in defining the issues of concern to them, in making decisions about factors that affect their lives, in formulating and implementing policies, in planning, developing and delivering services and in taking action to achieve change" [2].

Volunteering would also be one of the important components of social capital at the level of community [3]. Jenner [4] defines a volunteer as "a person who, out of free will and without wages, works for a not-for-profit organization which is formally organized and has as its purpose service to someone or something other than its membership".

\section{The Women's Health Volunteer programme}

Although most volunteers give their efforts to non-profit organizations, a noticeable proportion of all volunteer activity is directed to the public sector [5]. The Women's Health Volunteer (WHV) programme, as governmentbased voluntary action, is a national plan which was launched in some urban parts of the Islamic Republic of Iran in 1990-1991. This community-based health programme has gradually been expanded to all the urban parts of the country [6]. The WHVs (rabetine-behdashti in Farsi) are women who voluntarily participate in community health-based programmes. There is evidence that WHV activities could have positive effects on community health $[6,7]$. Therefore, we selected this programme to study, as a successful programme in the context of people's engagement with community healthbased programmes.

\section{Influencing factors on individuals' willingness to volunteer}

There are various factors, such as personal, family, and local characteristics, that could influence individuals' willingness to volunteer. Recently, researchers have paid particular attention to the influence of social network characteristics on personal decisions. Indeed, it is believed that social networks are central to various social processes affecting health-related behaviours [8]. A social network is a set of actors who may have relationships with one another [9]. Tindall and Wellman also define social network as "the study of social structure and its effects" [10].

Social network characteristics may be stratified in 3 dimensions. The first dimension is structural characteristics (size, density and network composition). The second is interaction characteristics (relation type, contact frequency, relation permanency, and intimacy with network members which is evaluated by closeness sensation of subject with network members). The third dimension is functional characteristics (various types of support consisting of emotional, advisory, monetary, physical, and time support) [11,12]. Individuals can obtain different types of support from their network members. Relatives, friends, and neighbours as well as colleagues can be important resources to offer help and support. It is believed that diverse connections could create various types of social support for each person. It is also supposed that the more diverse connections in one's personal social network, the better one's access to a widespread range of different types of support [12].

In the Islamic Republic of Iran, although a number of studies have been carried out concerning the sociodemographic factors of WHVs as well as the influence of their activities on community health $[7,13]$, less attention has been paid to the effect of contextual factors on volunteering. The impact of sociodemographic and social network characteristics on individuals' decisions to volunteer would still be a fruitful field for exploration.

This study was conducted to assess the relationship between sociodemographic and social network characteristics, and women's willingness to participate with Iran's WHV programme.

\section{Methods}

\section{Sampling and study population}

We conducted this case-control study in 2010 in Korasan-e-Razavi Province, one of the largest and most populous provinces in the country. It has roughly 5.5 million inhabitants (about $7 \%$ of the Iranian population). To select the samples, we restricted the selection process by some potential confounding variables: age, education level, marital status and job. Our research population was married women who were housewives, aged 15-49 years, with an education of between 6 and 12 years, living in urban parts of the province.

To calculate the required sample size, we first conducted a pilot study on 20 individuals from the population. From this we identified the potential problems of the data collection phase and to determine $P_{1}$ and $P_{2}$. We then used the equation below to estimate the sample size for each group:

$$
n=\left[2\left(\mathrm{Z}_{1-\alpha / 2}+\mathrm{Z}_{1-\beta}\right)^{2} P(1-P)\right] /\left(P_{1}-P_{2}\right)
$$

Where $P=\left(P_{1}+P_{2}\right) / 2$ and considering $Z_{1-\alpha / 2}=1.96$ and $Z_{1-\beta}=0.84$ (i.e. a power of 0.80 ), we calculated different sample sizes ranging from 62 to 96 samples in each group. As we applied a 2-stage cluster sampling method to select the samples, we considered 
the design effect equal to 1.5. So, our sample size was estimated at 145 samples in each of the case and the control groups. To control potential problems during data gathering, the researchers increased the sample size to 150 participants for each group.

There are nearly 175 urban health centres in Khorasan-e-Razavi province. The WHV programme is actively implemented among 150 centres. To select the participants, we randomly selected 50 of these centres as clusters and administered questionnaires to 3 women as cases in each cluster. All the respondents were women who had recently volunteered for participation in the WHV programme in the selected centres during the research period, 1 May 2010 to 1 September 2010.

In the Islamic Republic of Iran nearly all family members, including women, are registered in family health dossiers which are kept in the urban health centres. After data gathering for the cases, we randomly selected 3 controls in each of the centres among women who did not participate in the WHV programme and had not previously had any cooperation with similar programmes. The questionnaires then were administered via face-to-face interview.

There were 50 interviewers in our study. To assure quality and eliminate potential interviewer bias, a 1-day workshop was held for the interviewers. Additionally, an interview guide was made to use in the process of interviewing. The researchers also used a coding system for the questionnaires to control potential bias in both data entry and analysis and to ensure anonymity for the participants.

\section{Data collection tool}

We used a 2-section questionnaire to collect data. Internal consistency was assessed using Cronbach's alpha (0.73 in the social network characteristics domain). Reliability of the questionnaire was assessed via test-retest with a mean intra-class correlation coefficient of 0.82 (0.74-1.00).

The first section of the questionnaire covered sociodemographic characteristics including length of residence in her neighbourhood, the age and education level of the respondent and her husband, husband's job, and family size. We also collected data on other factors including presence of a child under 2 years old in the family, and home ownership. To evaluate the family wealth index, we used a list of assets such as vacuum cleaner, washing machine, dishwasher, telephone line, motor car, computer, refrigerator, colour television, and CD or DVD player. We then measured family wealth index via principle component analysis. In the final part of this section, we used a 5-point Likert-range question to assess quality of life and selfrated health status as well as a 7-point Likert-range question to evaluate neighbourhood intimacy as perceived by the respondent.

The second section of the questionnaire was allocated to individual social network factors comprising the structural, interactional and functional characteristics. The structural factors were size, density and network composition. Interactional characteristics consisted of relation type, contact frequency, relation permanency, and intimacy with network members. In this study, 5 types of support-emotional, advisory, monetary, physical, and time support - were considered social network functional characteristics.

\section{Data analysis}

We entered the data into Stata, version 10 . We evaluated differences between case and control groups via the Mann-Whitney U-test, $\chi^{2}$ and Fisher exact test. Using univariate and multiple logistic regression with odds ratio (OR), $P$-value and 95\% confidence interval. We assessed the association between volunteering and sociodemographic as well as social network characteristics. All independent variables were entered separately in the univariate logistic regression model. Then, as Jewell indicated, those variables with $P<0.2$ were selected for entering in multiple logistic regression [14]. In the final model, variables with $P<0.05$ were reported as statistically significant.

\section{Ethical considerations}

The researchers obtained the approval of the institutional review board of Tehran University of Medical Sciences. Before conducting the research, the research team obtained the authority of managers in regard to the research project. Agreement of all participants to participate the research was obtained before the interviews. As the interviews were prolonged (roughly 1 hour), respondents were offered rest breaks. The respondents were informed of their rights to cease their participation at any time during the interview.

\section{Results}

For the data analysis, we used 291 (out of 300) completed questionnaires (cases $=145$, controls $=146)$, a refusal rate of 3\%. The mean age in the case group was 28.84 (SD 8.26) years and the duration of education was 10.06 (SD 2.08) years; in the control group the corresponding values were 29.59 (SD 6.9) years and 9.91 (SD 2.07) years, respectively.

Table 1 shows the respondents' sociodemographic characteristics and their associations with participation in the WHV programme. Some sociodemographic factors, including the presence of a child under 2 years $(P=$ $0.020)$, quality of life $(P=0.018)$ and neighbourhood intimacy $(P=0.002)$, had $P<0.05$ in univariate logistic regression.

Table 2 shows the social network characteristics and their associations with volunteering. Social network 


\begin{tabular}{|c|c|c|c|c|c|c|c|}
\hline \multirow[t]{2}{*}{ Variable } & \multicolumn{2}{|c|}{$\begin{array}{c}\text { Case } \\
(n=145)\end{array}$} & \multicolumn{2}{|c|}{$\begin{array}{l}\text { Control } \\
(n=146)\end{array}$} & $\begin{array}{l}\text { Crude } \\
\text { OR }\end{array}$ & $P$-value & $95 \% \mathrm{Cl}$ \\
\hline & \multicolumn{2}{|c|}{ Mean (SD) } & \multicolumn{2}{|c|}{ Mean (SD) } & & & \\
\hline $\begin{array}{l}\text { Length of residence in neighbourhood } \\
\text { (months) }\end{array}$ & \multicolumn{2}{|c|}{$99.57(92.61)$} & \multicolumn{2}{|c|}{$86.10(93.52)$} & 1.00 & 0.342 & $0.99-1.00$ \\
\hline No. of siblings & \multicolumn{2}{|c|}{$5.02(2.34)$} & \multicolumn{2}{|c|}{$4.92(2.06)$} & 1.07 & 0.277 & $0.95-1.20$ \\
\hline Husband's age (years) & \multicolumn{2}{|c|}{33.54 (8.74) } & \multicolumn{2}{|c|}{$34.17(7.73)$} & 0.99 & 0.870 & $0.97-1.03$ \\
\hline Husband's education (years) & \multicolumn{2}{|c|}{$9.76(3.02)$} & \multicolumn{2}{|c|}{$9.31(3.58)$} & 1.02 & 0.767 & $0.94-1.11$ \\
\hline Family size & \multicolumn{2}{|c|}{$3.37 *(1.20)$} & \multicolumn{2}{|c|}{$3.62 *(1.13)$} & $0.83^{\mathrm{a}}$ & 0.100 & $0.66-1.04$ \\
\hline Quality of life & \multicolumn{2}{|c|}{$3.88 *(0.67)$} & \multicolumn{2}{|c|}{$3.66 *(0.69)$} & $1.60^{\mathrm{a}}$ & 0.018 & $1.09-2.37$ \\
\hline Self-rated health status & \multicolumn{2}{|c|}{$3.91(0.64)$} & \multicolumn{2}{|c|}{$3.84(0.70)$} & 1.17 & 0.389 & $0.82-1.68$ \\
\hline \multirow[t]{2}{*}{ Neighbourhood intimacy } & \multicolumn{2}{|c|}{$4.30 *(1.34)$} & \multicolumn{2}{|c|}{$3.68 *(1.39)$} & $1.40^{\mathrm{a}}$ & 0.002 & $1.14-1.72$ \\
\hline & No. & $\%$ & No. & $\%$ & & & \\
\hline \multicolumn{8}{|l|}{ Husband's job } \\
\hline Governmental & 22 & 16 & 23 & 16 & 1.00 & 0.902 & $0.50-2.20$ \\
\hline Free market & 84 & 61 & 92 & 63 & 1.05 & 0.779 & $0.27-5.63$ \\
\hline Retired & 4 & 34 & 5 & 3 & 1.24 & 0.655 & $0.18-2.96$ \\
\hline Private office & \multicolumn{2}{|l|}{6} & 6 & 4 & 0.73 & 0.663 & $0.48-3.21$ \\
\hline Worker & 20 & 14 & 18 & 12 & 1.24 & 0.840 & $0.16-9.90$ \\
\hline Unemployed & 2 & 2 & 2 & 2 & 1.24 & & \\
\hline \multicolumn{8}{|l|}{ Child under 2 years } \\
\hline Yes & 20 & 14 & 47 & 32 & $1.00^{\mathrm{a}}$ & 0.020 & $0.21-0.88$ \\
\hline No & 125 & $86^{*}$ & 99 & $68^{*}$ & $0.43^{\mathrm{a}}$ & & \\
\hline \multicolumn{8}{|l|}{ House ownership } \\
\hline Owner & 63 & 44 & 55 & 38 & 1.00 & 0.689 & $0.50-1.58$ \\
\hline Tenant & 57 & 39 & 72( & 49 & 0.89 & 0.492 & $0.60-2.87$ \\
\hline Other & 25 & 17 & 19 & 13 & 1.31 & & \\
\hline \multicolumn{8}{|l|}{ Wealth index } \\
\hline 1 (poorest) & 34 & 23 & 27 & 19 & 1.00 & 0.509 & $0.29-1.85$ \\
\hline 2 & 30 & 21 & 27 & 19 & $0.73^{\mathrm{a}}$ & 0.844 & $0.45-1.91$ \\
\hline 3 & 28 & 19 & 27 & 19 & $0.93^{a}$ & 0.089 & $0.20-1.12$ \\
\hline 4 & 27 & 19 & 30 & 21 & $0.47^{\mathrm{a}}$ & 0.181 & $0.29-1.27$ \\
\hline 5 (richest) & 26 & 18 & 31 & 22 & $0.60^{\mathrm{a}}$ & & \\
\hline
\end{tabular}

${ }^{*} P<0.05$ (Mann-Whitney $U$-test, $\chi^{2}$ test, Fisher's exact test).

${ }^{a}$ Variables with $P<0.2$ and considered for multiple logistic regression.

$O R=$ odds ratio; $C I=$ confidence interval.

density $(P=0.012)$ and heterogeneity $(P<0.001)$, women's intimacy with their network members $(P<0.001)$ and emotional $(P<0.001)$ as well as advisory $(P<0.001)$ support obtained from network members also had $P<0.05$ in the univariate model. We therefore entered these variables, together with those which had $P<$ 0.20 (i.e. wealth index and family size), in the multiple logistic regression analysis.
The results of the multiple logistic regression analysis are shown in Table 3. There were significant associations between volunteering and some sociodemographic factors including presence of a child under 2 years [adjusted OR $(A O R)=0.46]$, family size $(A O R=0.76)$ and neighbourhood intimacy $(\mathrm{AOR}=1.31)$ and some social network characteristics including type of acquaintance (which implies social network heterogeneity)
$(\mathrm{AOR}=0.60)$ and emotional support obtained. We compared no support (level 1) with a little support (level 2) conditions $(\mathrm{AOR}=1.80)$, no support with enough support (level 3) conditions $(\mathrm{AOR}=1.82)$ for emotional support obtained, as well as advisory support obtained in comparison with no support to a little support conditions $(\mathrm{AOR}=1.48)$ and no support to enough support conditions (AOR $=2.13$ ) 


\begin{tabular}{|c|c|c|c|c|c|}
\hline Variable & $\begin{array}{l}\text { Volunteers } \\
(n=145)\end{array}$ & $\begin{array}{l}\text { Controls } \\
(n=146)\end{array}$ & $\begin{array}{l}\text { Crude } \\
\text { OR }\end{array}$ & $P$-value & $95 \% \mathrm{Cl}$ \\
\hline \multicolumn{6}{|c|}{ Social network domain: structural } \\
\hline Ego network size [mean (SD)] & $12.79(7.43)$ & $12.99(5.62)$ & 1.02 & 0.294 & 0.99-1.05 \\
\hline Density [mean (SD)] & $0.64(0.18)$ & $0.70(0.18)$ & $0.13 a$ & 0.012 & $0.03-0.64$ \\
\hline \multicolumn{6}{|l|}{ Type of acquaintance [No. (\%)] } \\
\hline Non-relative & $457(27)$ & 264(15) & 1.00 & & \\
\hline Relative & $1257(73)^{*}$ & $1499(85)^{*}$ & $0.48 \mathrm{a}$ & $<0.001$ & $0.38-0.62$ \\
\hline \multicolumn{6}{|c|}{ Social network domain: interactional } \\
\hline Intimacy with others [mean (SD)] & $3.99 *(1.21)$ & $3.70 *(1.34)$ & 1.19a & $<0.001$ & $1.06-1.34$ \\
\hline \multicolumn{6}{|l|}{ No. of contacts [No. (\%)] } \\
\hline > once a week & $898(53)$ & $921(53)$ & 1.00 & & \\
\hline once a week & $342(20)^{*}$ & $372(21)^{*}$ & 0.94 & 0.646 & $0.73-1.21$ \\
\hline once in 2 weeks & $157(9)^{*}$ & $87(11)^{*}$ & 0.86 & 0.487 & $0.57-1.31$ \\
\hline$<$ once in 2 weeks & $306(18)^{*}$ & $273(15)^{*}$ & 1.15 & 0.414 & $0.82-1.61$ \\
\hline \multicolumn{6}{|l|}{ Relationship [No. (\%)] } \\
\hline Visual & $1246(75)$ & $1374(79)$ & 1.00 & & \\
\hline By telephone & $396(24)^{*}$ & $365(21)^{*}$ & 1.20 & 0.244 & $0.89-1.62$ \\
\hline By mail & $7(0)^{*}$ & $4(0)^{*}$ & 1.93 & 0.424 & $0.39-9.67$ \\
\hline Other & $10(1)^{*}$ & $6(0)^{*}$ & 1.84 & 0.345 & $0.52-6.49$ \\
\hline Relationship duration (months) [mean (SD)] & $203.94(143.49)$ & $196.87(134.52)$ & 1.00 & 0.505 & 0.99-1.00 \\
\hline \multicolumn{6}{|c|}{ Social network domain: functional } \\
\hline \multicolumn{6}{|l|}{ Emotional support [No. (\%)] } \\
\hline None & $170(10)$ & $401(23)$ & 1.00 & & \\
\hline A little & $631(37)^{*}$ & $680(38)^{*}$ & $2.19 \mathrm{a}$ & $<0.001$ & $1.58-3.03$ \\
\hline Enough & $913(53)^{*}$ & $680(39)^{*}$ & $3.17 \mathrm{a}$ & $<0.001$ & $2.20-4-56$ \\
\hline \multicolumn{6}{|l|}{ Advisory support [No. (\%)] } \\
\hline None & $294(17)$ & $562(32)$ & 1.00 & & \\
\hline A little & $656(38)^{*}$ & $678(39)^{*}$ & $1.85 \mathrm{a}$ & $<0.001$ & $1.45-2.36$ \\
\hline Enough & $762(45)^{*}$ & $518(29)^{*}$ & $2.81 \mathrm{a}$ & $<0.001$ & $2.09-3.78$ \\
\hline \multicolumn{6}{|l|}{ Monetary support [No. (\%)] } \\
\hline None & $931(54)$ & $962(55)$ & 1.00 & & \\
\hline A little & $399(23)$ & $359(20)$ & 1.15 & 0.409 & $0.83-1.60$ \\
\hline Enough & $379(22)$ & $431(25)$ & 0.91 & 0.550 & $0.66-1.24$ \\
\hline \multicolumn{6}{|l|}{ Physical support [No. (\%)] } \\
\hline None & $583(34)$ & $639(37)$ & 1.00 & & \\
\hline A little & $614(36)$ & $606(35)$ & 1.11 & 0.504 & $0.81-1.52$ \\
\hline Enough & $493(30)$ & 496 (28) & 1.09 & 0.599 & $0.79-1.51$ \\
\hline \multicolumn{6}{|l|}{ Time support [No. (\%)] } \\
\hline None & $542(32)$ & $614(35)$ & 1.00 & & \\
\hline A little & 644 (38) & $638(36)$ & 1.14 & 0.344 & $0.87-1.51$ \\
\hline Enough & $515(30)$ & 496 (29) & 1.18 & 0.316 & $0.86-1.62$ \\
\hline
\end{tabular}

${ }^{*} P<0.05$ ((Mann-Whitney $U$ test, $\chi \chi^{2}$ test, Fisher's exact test).

${ }^{a} P<0.2$ and considered for multiple logistic regression,

$O R=$ odds ratio; $C l=$ confidence interval.

$S D=$ standard deviation . 


\begin{tabular}{|c|c|c|c|}
\hline Variable & Adjusted OR & $P$-value & $95 \% \mathrm{Cl}$ \\
\hline Family size & 0.76 & 0.027 & $0.60-0.97$ \\
\hline Quality of life & 1.41 & 0.108 & $0.93-2.14$ \\
\hline Neighbourhood intimacy & 1.31 & 0.018 & $1.05-1.64$ \\
\hline Density & 0.17 & 0.075 & $0.026-1.19$ \\
\hline \multicolumn{4}{|l|}{ Child under 2 years } \\
\hline No & 1.00 & & \\
\hline Yes & 0.46 & 0.037 & $0.22-0.96$ \\
\hline \multicolumn{4}{|l|}{ Wealth index quintile } \\
\hline 1 (poorest) & 1.00 & & \\
\hline 2 & 0.66 & 0.382 & $0.26-1.68$ \\
\hline 3 & 0.94 & 0.884 & $0.41-2.15$ \\
\hline 4 & 0.44 & 0.123 & $0.16-1.25$ \\
\hline 5 (richest) & 0.79 & 0.588 & $0.34-1.84$ \\
\hline \multicolumn{4}{|l|}{ Type of acquaintance } \\
\hline Non-relative & 1.00 & & \\
\hline Relative & 0.60 & $<0.001$ & $0.47-0.77$ \\
\hline Intimacy with others & 1.01 & 0.875 & $0.90-1.13$ \\
\hline \multicolumn{4}{|l|}{ Emotional support } \\
\hline None & 1.00 & & \\
\hline A little & 1.80 & $<0.001$ & $1.31-2.46$ \\
\hline Enough & 1.82 & 0.003 & $1.22-2.72$ \\
\hline \multicolumn{4}{|l|}{ Advisory support } \\
\hline None & 1.00 & & \\
\hline A little & 1.48 & 0.007 & $1.11-1.96$ \\
\hline Enough & 2.13 & $<0.001$ & $1.52-2.99$ \\
\hline
\end{tabular}

$O R=$ odds ratio $; C I=$ confidence interval.

\section{Discussion}

To the best of our knowledge, this is the first study conducted in Iran that deals with the association between sociodemographic and social network factors and willingness to participate in a voluntary programme. By recognizing these potential associations, a new view could be created to improve such programmes.

Multiple logistic regression analysis indicated that neighbourhood intimacy and the emotional and advisory support obtained from network members may have a direct association with willingness to volunteer in the WHV programme, while presence of a child under 2 years in the family, family size and network homogeneity may have an inverse association. We found no significant associations between certain sociodemographic variables and social network characteristics and participation in the WHV programme.

\section{Arguments and counterarguments}

Family size was an influencing variable on volunteering. The smaller the family size, the more likely respondents were to participate in the WHV programme. As these women may have more time to participate in social activities, this would be logical. Nesbit also suggested that middle-aged women with larger family size have less time to engage in voluntary activities [15].

There was a significant association between presence in the family of a child under 2 years and volunteering. This is similar to the findings of Gomez and Gunderson who reported an association between the existence of a dependent child in the family and volunteering [16]. There was also a significant association between neighbourhood intimacy and volunteering in our research. Poley and Stephenson indicated strategies which develop common interests in their neighbourhood could have positive effects on neighbourhood members' civic engagement [17].

We found the number of non-relative members (friends and neighbours) in the social networks of volunteers was statistically significantly greater than in the social networks of the control group. In fact, the social networks in the volunteers were more heterogeneous than those of the controls. Diversity in 
their personal social network may imply that an individual is more communicative, and this may be a predictor of willingness to volunteer. Our finding was similar to those of Wilson and Musick, which showed a direct association between number of friends and voluntary activity [18].

Our results showed a significant association between the emotional and advisory support, as personal social network resources, and willingness to volunteer in the WHV programme. It was comparable with the results of the study of Tong, Hung and Yeun in Macao, which was conducted to recognize the determinants and effects of social network characteristics on pro-social behaviours such as volunteering and helping others [19]. They emphasized those individuals who have resourceful social networks have more willingness to participate in such pro-social activities.

In contrast, in our study, there was no significant association between social network size and willingness to volunteer. In the study carried out by Tong, Hung and Yeun, social network size may have had a direct association with personal willingness to help others and volunteering. As their study could not investigate temporality between exposure (social network size) and outcome (volunteering), the network size may itselfbe influenced by volunteering. As we used incident cases, there was no similar problem in our study.

There was no significant association between wealth status of the participants and volunteering in our study. In contrast, Goss implied that wealthy people are more willing to donate their time in voluntary efforts [20].

Although several studies have reported an association between home ownership and volunteering $[21,22]$ we did not find such an association. Insufficient sample size may be a cause of the failure to find this association in our study. Neither did we find a significant association between social network density and volunteering, which was comparable to the results of Rotolo [23], but contrary to those of Kane [24].

\section{Study limitations}

Case-control studies are known to have more of a tendency to confounding, information bias and selection bias than other types of study. To control the problem, we restricted the selection of subjects on some variables such as age (15-49 years), duration of education (6-12 years), marital status (married) and job (housewife). We also conducted some activities to improve quality assurance, such as holding a workshop for interviewers and preparing an interview guide. To avoid the effect of volunteering on the factors under study, especially social network characteristics, all the selected cases were new volunteers (incident cases).

We would particularly refer to 2 issues. Although many studies have demonstrated a potential relation between education level and volunteering [25], we could not investigate the association between the variables. This was because of the restriction on this factor in the selection process. Similarly, associations between volunteering and the respondents' age, marital status, and job could not be evaluated in this study. Besides, a woman who is willing to participate in the WHV programme must obtain written agreement from her husband. This behaviour may be a proxy for a more democratic family. So it seems women living in such families may have more chance to participate in social activities such as the WHV programme. Therefore, our results might be influenced by this discrepancy between the volunteer group and the control group. Of course, this association should be investigated through a separate study.

\section{Policy implications}

As mentioned, there has been no previous research to identify the characteristic factors of women who have a propensity to participate in the Iranian
WHV programme, as a voluntary plan. Our findings can be used by policymakers who work on community-based voluntary programmes, especially in the Islamic Republic of Iran and other countries with similar cultures. According to our findings in regard to the relationship between volunteering and family size as well as the presence of a child under 2 years in the family, we suggest that managers should probably target their attempts at women who have small families, with no dependent children so that they may be able to select appropriate individuals for their voluntary programmes.

We found that the greater the intimacy in the neighbourhood, the greater the chance of a woman being willing to volunteer. To promote a volunteering culture in the community, places such as "neighbourhood houses" (c.f. community centres) or "neighbourhood councils" could be established. Through such places, neighbours could design and generally run public activities, including educational and health/ exercise activities. The likelihood of more-communicative persons, i.e. those with a propensity for volunteering, attending such places would be quite high. So, we suggest establishing places such a "neighbourhood house", because of these multi-dimensional effects.

In conclusion, family size, neighbourhood intimacy, individual social network heterogeneity and received emotional and advisory supports from network members may be important determinants of participation in community-based voluntary programmes such as the WHV programme.

\section{Acknowledgement}

This paper is based on the first author's $\mathrm{PhD}$ dissertation, supervised by the second author and submitted to the Epidemiology and Biostatistics Department, Tehran University of Medical Sciences, 2010 and granted by the University. 


\section{References}

1. Baum FE, Ziersch AM. Social Capital. Journal of Epidemiology and Community Health, 2003, 57:320-323.

2. Community participation in local health and sustainable development: approaches and techniques. Geneva, World Health Organization, 2002 (European Sustainable Development and Health Series 4) (https://www.utexas.edu/nursing/norr/ docs/commparticipation.pdf, accessed 15 February 2013).

3. Cox E. Building social capital. Health Promotion Matters, 1997, 4:1-4.

4. Jenner JR. Participation, leadership, and the role of volunteerism among selected women volunteers. Journal of Voluntary Action Research, 1982, 11(4):27-38.

5. Brudney JL, Kellough JE. Volunteers in state government: involvement, management, and benefits. Nonprofit and Voluntary Sector Quarterly, 2000, 29(1):111-130.

6. Vahidnia F. Case study: fertility decline in Iran. Population and Environment, 2007, 28(4-5):259-266.

7. Ramazani AA, Miri MR, Shayegan F. [Effect of health education on health coordinating volunteers of Birjand health center to promote healthy life styles in the community]. Journal of Birjand University of Medical Sciences, 2008, 14(4):9-15 [in Farsi].

8. Marsden PV. Network methods in social epidemiology. In: Oakes JM, Kaufman JS, eds. Methods in social epidemiology. San Francisco, Jossey-Bass, 2006:267-286.

9. Hannemann RA, Riddle M. Introduction to social network methods. Riverside, California, University of California, Riverside, 2005 (ch 2) (http://faculty.ucr.edu/ hanneman/nettext/, accessed 15 February 2013).

10. Tindall D, Wellman B. Canada as social structure: social network analysis and Canadian sociology. Canadian Journal of Sociology, 2001, 26(2):265-308.

11. Israel BA, Antonucci TC. Social network characteristics and psychological well-being: A replication and extension. Health Education Quarterly, 1987, 14(4):461-481.

12. Bastani S, Salehi M. [Network social capital and gender: Investigation of structural, interactional and functional characteristics of social network of men and women in Tehran]. Social Science Letter, 2007, 30:63-93 [in Farsi].

13. Ganji $F$ et al. [Evaluation of the impact of participatory intervention in the reduction of unnecessary caesarian (deliveries) in Shahrekord, Iran]. Shahrekord University of Medical Sciences Journal, 2006, 8(1(29)):14-18 [in Farsi].
14. Jewell NP. Statistics for epidemiology. California, Chapman \& Hall/CRC, 2004

15. Nesbit B. A comparison of volunteering data in the panel study of income dynamics and the current population survey. Nonprofit and Voluntary Sector Quarterly, 2010, 39(4):753-761.

16. Gomez R, Gunderson M. Volunteer activity and the demands of work and family. Industrial Relations/Relations Industrielles, 2003, 58(4):573-589.

17. Poley L, Stephenson M. Community, trust and the habits of democracy: an investigation into social capital and civic engagement in U.S. cohousing neighborhoods (paper presented at the Annual Meeting of the American Political Science Association, Chicago, 30 August-2 September 2007). 2007 (http:// citation.allacademic.com//meta/p_mla_apa_research_citation/2/0/9/9/8/pages209987/p209987-1.php, accessed 15 February 2013).

18. Wilson J, Musick MA. Social resources and volunteering. Social Science Quarterly, 1998, 79:799-814.

19. Tong KK, Hung EPW, Yeun SM. The quality of social networks: Its determinants and impacts on helping and volunteering in Macao. Social Indicators Research, 2011, 102(2):351-361.

20. Goss KA. Volunteering and the long civic generation. Nonprofit and Voluntary Sector Quarterly, 1999, 28(4):378-415.

21. Rohe W, McCarthy G, Van Zandt S. The social benefits and costs of homeownership: a critical assessment of the research. Washington DC, Harvard University, Joint Center for Housing Studies, 2001 (Low Income Home Ownership Working Paper Series LIHO-01.12) (http://www.jchs.harvard.edu/ sites/jchs.harvard.edu/files/liho01-12.pdf, accessed 15 February 2013).

22. Volunteering in America 2010: national, state, and city information. Washington DC, Corporation for National and Community Service, Office of Research and Policy Development, 2010 (http://www.theartofcivicengagement.org/files/IssueBriefFINALJune15.pdf, accessed 15 February 2013).

23. Rotolo T. Town heterogeneity and affiliation: a multilevel analysis of voluntary association membership. Sociological Perspectives, 2000, 43(2):271-289.

24. Kane DA. Network approach to the puzzle of women's cultural participation. Poetics, 2004, 32:105-127.

25. Erlinghagen $\mathrm{M}$, Karsten $\mathrm{H}$. The participation of older Europeans in volunteer work. Ageing and Society, 2006, 26(4):567-584. 